\section{INTERNATIONAL JOURNAL OF \\ DESIGN AND FASHION STUDIES}

VOLUME 3, ISSUE 2, 2020, 67-75.

www.egyptfuture.org/ojs/

\title{
Sustainability in flax fabric and the use of alternative local agricultural products in the Pharaonic era
}

\author{
Maha Aldabbagh a, *, Shahd Ibrahim Omar b \\ * \\ a Associate Professor \\ b Master Student
}

\begin{abstract}
Through the world's tendency towards sustainability and the use of renewable environmental materials as in ancient times, this study focused on the problems faced by weavers in the Pharaonic era, as the textile industry in most countries of the world is considered an environmental craft industry that uses in its manufacture the local raw materials available in each country. The study's questions were: What are the local environment materials used in the fabric in the Pharaonic era? How did the pharaohs when weaving deal with the lack of linen? The study relied on the historical approach because of its description and recording of the facts and past events, and through previous studies it is clear that most of them agreed with the current study in Being using the historical method in the study of the Egyptian tissues as a study (Hussein 1969 AD) and (Ammar 1976 AD) and (Al-Zoghbi) and (Al-Khwas 1976) also stressed the importance of using linen in the fabric and how the pharaohs dealt with its shortage and cover the needs with natural materials in that era and there Also study (Dr. Bagh, 2013), which cared about sustainability and the use of environmental materials to preserve the environment, the traditional heritage. There is also a study (Al-Rifai 2016) and (Hassan and Shaker 2013 AD) were explaining the importance of flax and its specifications and needs for its growth, and the ability to use it to use it optimally without causing environmental pollution as a study (Zamani, 2014), Tobler-Rohr, 2011, and Blackburn, 2009, which addressed textile and strategic trends to keep pace with the global development of sustainability and the use of oil alternatives in tissues with environmentally friendly materials.
\end{abstract}

\begin{tabular}{ll}
\hline Keywords & \\
- & Sustainability \\
- & Fabric \\
- & Flax \\
- & Haraonic era
\end{tabular}




\section{Introduction}

Sustainability aims to enable people allover the world to meet their basic needs and enjoy a better life without compromising the needs of next generation.

It is also acomprehensive development concept that serves present generations.

The textile industry, in most countries of the world, is a sort of environment- based craft that utilize available local raw materials. The origin of these industries in Egypt dates back to ancient times, as fabrics makers and craftsmen at that time were famous for making fabrics and textile, utilizing local agricultural crop, such as cotton and linen. When plant crops are lacking, the fabrics' needs were met by the use of animal-based materials, such as wool, lint, hair and leather, that were available in the same local environment, although linen was the most common fabric in ancient Egypt.

Although Egyptians have known other types of fabrics, they preferred to wear flaxbased linen clothes. They used flax plants due to its availability in abundance, thanks tothe good climate and the availability of astrong source of water from the Nile River. Meanwhile, Ancient Egyptians believed that fabrics made from animal-based materials, such as wool, are impure, and this was the reason why linen, which is extracted from a plant, was commonly used in ancient Egypt. Apart from this, animalbased clothes, such as animal skin was dedicated to priests, and eventually, the upper classes of ancientEgyptian citizens were commonlydistinguished by their wearing of animal- based clothes.

The Ancient Egyptians used linen as their most common clothes apart from small minorities, and classes of society at that time could be distinguished based on the quality of their clothes. Upper class community usedto wear high quality linen, whereas lowerclass used to wear clothes made of inferior materials. Moreover, the upper class used more sophisticated fabrics, designs, and shapes as well as dyed fabrics. These materials were expensive, and indicated the high status of their wearers. On the other hand, the cheaper and thicker type of linen was used by lower-class community, where the working class used to wear shorter clothes for better mobility in the fields. It is noteworthy that archaeologists were interested in textile studies because textile represents the culture that characterized that era.

\section{The Research Problem:}


The research problem can be summarized in the following questions: What are the local environment-based materials used in textile during the Pharaonic era? Why linen is considered a sustainable product?

\section{The Importance of the Research:}

The importance of the research springsfrom its interest on natural resources, the development of national economy, and spread of awareness on the importance of theuse of natural fibers to preserve the environment. Moreover, this research is an important tool that clarifies the concept of sustainability during the Pharaonic era, and solves recent problems pertaining to textile sustainability. It is also considered a source that can enrich the Arab and internationallibraries which are specialized in this area, and can also be utilized for the purposes of scientific and practical studies and researches.

\section{The Research Objective:}

- This research aims to identify the materials of the local agricultural environment that were used in the textileindustry during the Pharaonic era, and how the pharaohs dealt with the lack of flax plant.

- The research used the historical approach as it describes, documents, studies and interprets past facts and events, and then analyses them, based on accurate methodological and scientific bases, with the aim of reaching generalizations and facts that help understand the present time based on the events of the past, and to predict thefuture.

\section{Axis of Theoretical Study:}

\section{The first axis: Textile during the Pharaonic era:}

In his study, Textiles in Ancient Egypt, Noah dealt with the importance of linen in ancient Egypt, as history records the use, by the ancient Egyptians, of plants with coarse fiber for making fabrics, as well as for their daily needs. Flax was the most important type of these plants, and was even used and highly sanctified by the clergy, who used to present it as offerings to the gods. Moreover, linen rolls that had been used since the earliest eras, were also used for shrouding and embalming deceased persons. And because wool was commonly believed as impure, animal fibers were not of great importance in fabrics manufacturing. Therefore, ancient Egyptians preferred textile fibers over wool in making their different types of fabrics. (Noah, 1987)

The historical development of the textile industry and its preparation process has been dealt with in Hussein's study, Studies in the Development of Textile Arts and Printing,(Hussein, 1969). The study shed light on the people of the east and their interest in this ancient art industry at a time when the West was resisting the entry of such industries intoits territories, with the whole world recognizing the people of the East as the firstreference in the practice of arts and industries.

Meanwhile, Ariba's study "Textilethrough Different Eras" (Ariba 2015), hasdealt with the historical and technical information of textile by examining the textile industry 


\section{INTERNATIONAL JOURNAL OF \\ DESIGN AND FASHION STUDIES}

VOLUME 3, ISSUE 2, 2020, 67-75.

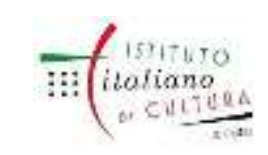

www.egyptfuture.org/ojs/

throughout the historicaleras, especially during the Pharaonic era, which was famous for the manufacture oflinen fabric. The study also investigated howthe Pharaohs dealt with shortage of linen,which was not abundant because it was awinter crop that was being cultivated for three months per annum only, in conjunctionwith beans and clover plants. Another reasonfor the shortage of linen at that time was the fact that such plant usually takes long time todry and needs a special care, as the fiberbreaks easily and often results in a low- quality crop that could only be used in making ropes and clothes for ordinary people. In addition, few crops only were of high quality and was being used as gifts between the pharaohs of Egypt and kings of ancient world. It was also considered traditional dowries in that era, and a commodity that can be traded for other products.

Natural raw materials and other plant products with positive results and better sustainability, such as cotton, were used to compensate the shortage of basic raw material. The study has also shed light on the methods used in textile coloring process and demonstrated how the ancient used alum to boost color sustainability. It has also analyzed decorations of textile at that era, and drew the attention to the high level of splendor and perfection of decoration, a quality that is difficult to attain nowadays.

In a study titled, History of Egyptian Textile Art, the authors (Ammar, Abdel Rahman 1974) dealt with the traditional methods for textile manufacturing, ways of textile decoration that were used in past eras, and ways to compensate the shortage of basic raw material with another environmental materials that give positive results. The study examined the most important tapestries, and analyzed and subdivided textile decorations into plant, geometric, human, animal and written decorations. The study has also explained thehistorical sequence of the emergence of these decorations and their evolution over time.

Nasr and Zoghbi's study, Studies inTextiles, aimed to identify the beauty and magnificence of textile and the different ways of weaving textiles. It also aimed to identify the intertwining of plant tissues, where the ancients used to compensate the shortage of fibers with similar materials. (Nasr and Zoghbi, 2004)

Meanwhile, in his study, Spontaneity in the Art of Weaving, Maher sought to demonstrate the beauty and magnificence of textiles. He examined the methods that had been applied throughout the Pharaonic times, in addition to the different methods of weaving that were applied throughout the ages, including tapestries. Maher (1962).

Al-Khawas' study, Technical Characteristics of Tapestries, was a sort of historical, analytical and descriptive study that dealt with the aspects of tapestries being a feature of the successive Egyptian eras, which has a reciprocal effect with those eras. The study focused on the artistic features or the artistic merits of the Egyptian eras, and looked for ways to bring it back to its artistic origin, because of its ease and accuracy that begin to dwindle nowadays. (Al-Khawas, 1976) 


\section{INTERNATIONAL JOURNAL OF \\ DESIGN AND FASHION STUDIES}

VOLUME 3, ISSUE 2, 2020, 67-75.

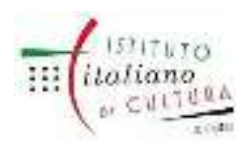

www.egyptfuture.org/ojs/

\section{Second Axil: Sustainability and NaturalResources}

Another study titled, Natural Resources and Constituents Affecting Economic Production, has analyzed the importance of natural resources for national economies, with a view to highlight the characteristics ofthese resources in terms of their ability or inability to regenerate, and the possibility of preserving or developing these resources. The study provided aspects for some trends that may help decision makers to take advantage of available natural resourcesaccording to the needs of the population, and in light of the materialistic and human potentials of the national economy. (Khair, 2014).

Al-Rifai's experimental study, Chemistry and Techniques of Goldsmiths and Textile Printing, has tested the specifications of natural and synthetic fibers, including linen which is considered exhaustive to agricultural land. The research shed light on dyeing process of natural and syntheticfibers, namely, the distinctive features of sink-dyeing of fibers, being not soluble in water and can be printed upon. (Al-Rifai,2016).

In another experimental study title, Effect of Nitrogen and Iron Fertilization at Two Levels of Field Capacity on Linen Growth and Yield Characteristics, the author . (Hassan and Shaker, 2013) has found that flax crop is sensitive to water stress throughout the stages of growth, and need a moisture content in the soil that is ready for absorption, and that it responds highly to nitrogen fertilizer and iron by increasing the characteristics of growth and seed density of plants.

In her study, Sustainability and Traditional Urban Fabric, Al-Dabbagh hasprovided a comparative scientific analysis to identify how to take advantage of environmental textile elements. The study has shed light on the role of environmental textile in the preservation of energy. The study has also recommended the adoption of 
local nature of construction as much as possible and reuse (or recycle) consumed building materials or materials or waste, being the most consumed element to produceenergy. (Al Dabbagh, 2013)

In his experimental study, The Role ofGreen Productivity Strategy In Achieving Sustainability of Environmental and Social Performance, Dawood has found that although the Iraqi Drilling Company applied some standards at varying proportions, yet it did not achieve sustainability forenvironmental and social performance. (Dawood, 2017)

In another analytical study, The Effect of Characteristics of Green Product on the Purchasing Behavior of Customer, the author(Sherif 2017) has recommended that production organizations provide adequate environmental information to customers inorder for them to design the green product using natural materials, and that state institutions control the organizations that produce green products because of lack of confidence among customers in health products. The study has also highlighted the need for clarifying some green environmental labels, as some customers find it difficult to understand these signs. The study has also recommended that organizations conduct environmental awareness campaigns to encourage customers buy their products.

In his analytical study, Design Quality of Production of Environmentally Friendly Clothing, the author (Mustafa 2010) has concluded that sulfur dyes can be used in a safe and environmentally friendly manner that help preserve the advantages of natural tissues (including cotton 100\% - linen) and thus sustainability of both cotton and linen fabrics can be preserved.

In their study, Sustainability Seen from the Perspective of Consumers, Bohm \& Hanss (Hanss \&Bahm 2012), aimed to find out how consumers understand the conceptof sustainability. In their paper, they report on a study among Norwegian consumers in which they explored their understanding of sustainability at two levels. First, they

investigated consumers' understanding of the general sustainability concept; specifically, how important the following five sustainability dimensions are in consumers' conception of sustainability: theenvironmental, social, economic, temporal and the developmental dimension.

Giovanni and Fabiti's study, What Is Sustainability, has shed light on various discussions that were often dealt with separately in some cases, thus limiting the actual implementation of sustainability by relying on a review of relevant literature on the concept of sustainability (or sustainable development), with the view to explore this idea by identifying its key dimensions and the interrelationships between them. (Giovanni and Fabiti 2013)

The sustainable development of textile waste management from both environmental and social perspectives was explored in Zamani's study "Towards Understanding Sustainable Textile Waste Management: Environmental Impacts and Social Indicators (Zamani, B. 2014).

The first part of this thesis investigates theenvironmental impact of different options for textile waste treatment. In Sweden, the predominant method of textile waste 
treatment is incineration. The question is whether this is environmentally optimal or whether an alternative should be pursued by policy- makers. For this reason, three alternative textile waste recycling techniqueswere examined. The findings show that by applying these recycling technologies, the recovered products can provide major environmental gains since they may be able to replace products from primary resources.

In another study titled: SustainableTextile Production: a Case Study from a Woven Fabric Manufacturing Mill in Turkey, the authors (2011, Tobler- Rohr) aimed to investigate the applicability of different sustainable production measuresand demonstrate environmental andeconomic benefits in a woven fabric manufacturing mill in Turkey. The results ofthe study show that the wide-spread uptakeof proposed sustainable production measures

would generate a tremendous change in the Turkish textile industry without a need for heavy investments in technology. Moreover, the economic returns would help Turkish textile industry to sustain its competitive position in the global textile market which faces a pressing challenge of low cost, high quality and environmentally benignproduction.

In his study, Experimental StudySustainable Textiles: Life Cycle AndEnvironmental Impact Examines Ways Of Improving Sustainability, Blackburn(Blackburn

2009) discusses howsustainability can be integrated into textiledesign, ensuring more sustainable productionof both natural and

synthetic fibres,improving sustainability in processes such asdyeing as well as more environmentally-friendly technologies including enzyme andplasma technologies. The study reviewsconsumer perceptions of recycled textiles,ecolabelling, organic textiles and the use ofrecycled materials in textile products

\section{Remarks on past studies}

It is clear that most studies are in conformity with the current study in that they used the historical approach in their studies of Egyptian tissues, such as the study of (Noah, 2), (Hussein, 1969), (Oraiba, 2015), (Amar, 1976), (Zoghbi, 2004) and Maher, 1962 and Al-Khawas, 1976. These studies also stressed the importance of using flax in the making of fabrics and how the Pharaohs dealt with the lack of flax and covered the needs of natural raw materials in that era, and the different ways of weaving and interweaving of plant tissues, where fibers were compensated by similar materialsto cover the shortage.

There is also a study by Aldabbagh (Dabbagh, 2014), which was concerned with sustainability and the use of environmental materials to preserve the environment and traditional heritage. There are also studies by Khair (Khair, 2014) and (Rifai, 2016) and (Hassan and Shaker, 2013), which illustrated the importance of linen, its specifications and growth requirements, and the ability to use it optimally without causing environmental pollution. Other studies by (David, 2017) (Sharif 2017) (Mostafa 2010) (Bohm \& Hanss 2012), (Giovanni, Fabiti 2013), (Zamani 2014), 


\section{INTERNATIONAL JOURNAL OF \\ DESIGN AND FASHION STUDIES}

ISSN: 2735-5365

(Tobler - Rohr, 2011)and Blackburn (2009), focused on textile andstrategic trends to keep pace with the global evolution of sustainability and the use of environmentally friendly materials.

Although the objectives of these studies differ from the objectives of the current study, yet it helped the researcher identify the reasons for the lack of flax crop in the Pharaonic era that forced the Pharaohs to useother local agricultural products.

The researcher reached the followingresults: The local environmental materials used in the Pharaonic era for making fabricswere cotton, linen, wool, lint, hair, andleather, and that the Pharaohs dealt with thelack of flax by using other fibers from localenvironment to cover the shortage of fabrics.It was also found that flax is a sustainable plant with several uses, such as making offabrics and textile, making of edible oil, medication, and food supplements.

However, the most valuable informationis that flax-based textile can withstand different environmental factors and stay for along period of time and reused or recycled without any impact on the environment. The pharaonic mummies are clear evidence on sustainability of linen.

History of ancient times have shown how great the sustainability of flax plant was, and how it was a good source to preserve the environment and traditional heritage.

\section{The recommendations were as follows:}

- Reducing the use of petrochemical products in fabrics' making, due to its harmful damage on environment; The use of local plant-based natural raw materials for fabrics' making;

- The use of similar environmentalmaterials that can give positive results and better sustainability to compensate the lack of basic raw material.

Bark-based raw materials, including jute, are considered the best alternatives to flax plants. Moreover, banana fibers were utilized recently as a good alternative to linen, because it has good properties such as absorption, good resistance to bacteria and ultraviolet radiation.

- Further studies could be done on how to increase the production of flax as well asto demonstrate the environmental and economic benefits of this plant.

\section{References}

- Noah (1), Heba Mustafa Kamal, Textiles in Ancient Egypt, Faculty of Archeology, Egypt, 5-2.

- Hussein (M), Mustafa Mohammed,studies in the development of textile arts and printing, Cairo, 180-195.

- Ariba (2015), Heba, Textile through different eras, Egypt State Information Service, the date of entry 7/6/1440 from the site. www.sis.gov.eg

- Ammar (1974), Abdel Rahman, theHistory of Egyptian textile art, Cairo,236.

- Zoghbi (2004), Insaf Nasr and Kawthar, Studies in Textiles, Beirut, 276. 


\section{INTERNATIONAL JOURNAL OF \\ DESIGN AND FASHION STUDIES}

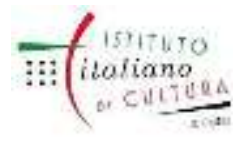

- Maher (1962), Suad, spontaneity in the art of weaving, the Egyptian General Authority for Authors and Publishing 101-105

- Al-Khawas (1976), Hala Abdel Aziz, Master Thesis, the technical characteristics of the tapestries and productive educational assets, Cairo, VIT.

- Dabbagh (M), Jassim Abboud, sustainability and traditional urban fabric, College of Engineering, No. 16, the date of entry 7/6/1440 e.

- Khair (2014), Hamid AdamMohammed, natural resources and constituents affecting economicproduction, Sudan, 67 - 110.

- Al-Rifai (2016), Bilal Abdul Wahab, Master Thesis, Chemistry and techniques of goldsmiths and textile printing, Damascus, 21.

- Hassan (2012), Ahmed Yassin, Shaker, and lyad Talaat, Ph.D. Thesis, Effect of Nitrogen and Iron Fertilization at Two Levels of Field Capacity on Linen

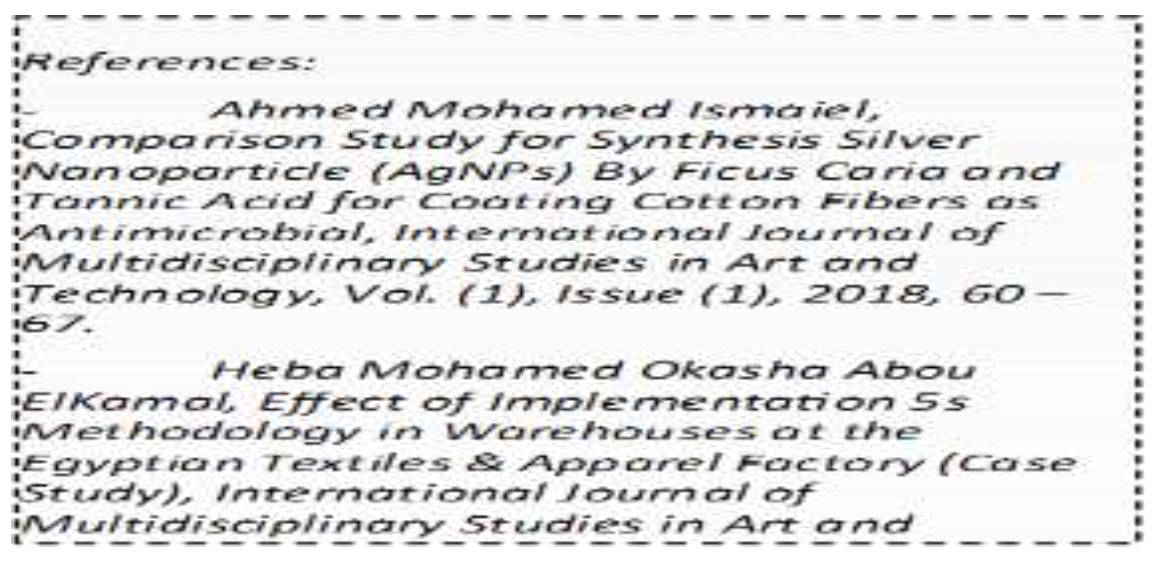

Received: April 2020

Accepted: June 2020 